\title{
Benefits and Pitfalls of Google Scholar
}

Francesca R. Jensenius ${ }^{\circledR}$, Norwegian Institute of International Affairs

Mala Htun, University of New Mexico

David J. Samuels, University of Minnesota

David A. Singer, Massachusetts Institute of Technology

Adria Lawrence, Johns Hopkins University

Michael Chwe, University of California, Los Angeles

This is a post-print of an article appearing in PS: Political Science \& Politics, published online: 13 June 2018 (https://doi.org/10.1017/S104909651800094X)

\begin{abstract}
:
Google Scholar (GS) is an important tool that faculty, administrators, and external reviewers use to evaluate the scholarly impact of candidates for jobs, tenure, and promotion. We highlight both the benefits of GS, including the reliability and consistency of its citation counts and its platform for disseminating scholarship and facilitating networking, as well as its pitfalls. GS has biases because citation is a social and political process that puts certain groups such as women, younger scholars, scholars in smaller research communities, and scholars opting for risky and innovative work at a disadvantage. GS counts also reflect practices of strategic citation that exacerbate existing hierarchies and inequalities. As a result, it is imperative that political scientists incorporate other data sources, especially independent scholarly judgment, when making decisions that are crucial for people's careers. External reviewers have a unique obligation to offer a reasoned, rigorous, and qualitative assessment of a scholar's contributions, and should therefore not use GS.
\end{abstract}

The ${ }^{\circledR}$ symbol indicates that the authors' names are in certified random order, as described in Ray and Robson (2018).

Francesca R. Jensenius is a Senior Research Fellow at the Norwegian Institute of International Affairs. She can be reached at francesca.jensenius@gmail.com.

Mala Htun is professor of political science at the University of New Mexico. She can be reached at malahtun@gmail.com.

David J. Samuels is Distinguished McKnight University Professor of Political Science at the University of Minnesota. He can be reached at dsamuels@umn.edu.

David A. Singer is associate professor of political science at Massachusetts Institute of Technology. He can be reached at dasinger@mit.edu.

Adria Lawrence is the Aronson Associate Professor of International Studies and Political Science at Johns Hopkins University. She can be reached at adria.lawrence@jhu.edu.

Michael Chwe is professor of political science at the University of California Los Angeles. He can be reached at michael@chwe.net. 
When political scientists sit on hiring committees, evaluate candidates for tenure and promotion, and write letters of recommendation, we are often called on to assess a scholar's "impact." We provide our subjective appraisal of the candidate's work, and compare the candidate against her or his peers. As they produce these sensitive and critical assessments, many political scientists rely for help on Google Scholar (GS) and other citation count tools.

GS is readily available and requires no registration or subscription. Writers of tenure and promotion evaluation letters, who until the early 2000s would engage in mostly qualitative analysis of a candidate's file, now routinely refer to GS citation counts. Many political scientists have set up GS profile pages, which conveniently list all of a scholar's published (and often unpublished) work, along with citation counts for each work and summary statistics including total citation counts by year. Many scholars mention their citation count on their CVs, and some departments require faculty to report it in their tenure files. ${ }^{1}$

Some people believe that citation counts are more objective than individual opinions about impact. Yet no objective metric of impact exists - of articles, books, journals, or individual scholars. Every metric contains built-in biases. Meanwhile, GS continues to be the discipline's de facto standard for assessment of scholarly impact despite a spirited discussion-scattered across blogs, journals, and conferences—of its drawbacks (see, e.g., Jascó 2005; Maliniak, Powers, and Walter 2013; Nexon 2016; Samuels 2011, 2013; Hendrix 2015). Since political scientists try hard to find unbiased measures to advance empirical arguments, it is especially odd to use a measure with so many obvious flaws to evaluate ourselves (on this, see Reiter 2016).

The purpose of this article is to amplify the discipline-wide discussion about evaluation criteria by reckoning with the benefits and the pitfalls of using GS to assess scholarly impact. ${ }^{2}$ Whereas the advantages we identify pertain primarily to GS, the disadvantages apply to almost all citation counts. The strengths of GS include incentives for quality, visibility, and open access; provision of a platform for networking; and the reliability and consistency of its citation counts. However, GS has biases because citation is a social and political process that puts certain groups such as women, younger scholars, scholars in smaller research communities, and scholars opting for risky and innovative 
over incremental work at a disadvantage. GS counts also reflect practices of strategic citation that exacerbate existing hierarchies and inequalities.

Many people will continue to use GS daily, which makes it imperative that we incorporate other data sources, especially independent scholarly judgment, when making decisions that are crucial for people's careers and lives. While GS is useful for visibility and scholarly communication, we recommend against its use by external reviewers for tenure and promotion. GS counts should not have a double impact by figuring into both departmental and external evaluations. Instead, the unique role and obligation of expert external reviewers is to offer a reasoned, rigorous, and qualitative assessment of a scholar's contributions.

\section{The Rise of Google Scholar and How it Works}

Google Scholar (www.scholar.google.com) (GS) was created in 2004 as a search engine for academics. Like Google's general search engine, it generates results based on the strength of the link between search terms and how often and how recently a work has been cited. GS indexes virtually everything available on the web in any language, including journal articles, academic books and book chapters, and non-peer-reviewed material such as conference papers, working papers, theses, and dissertations. ${ }^{3}$

GS also ranks the top 20 journals in a discipline. At the top of the GS home page, the "Metrics" button provides links to rankings by discipline and language, using an "H5 index" - the number $\mathrm{X}$ of articles that have at least X citations in the last five years. Inexplicably, GS does not include international relations journals in its "top publications - political science" list.

Since 2012, Google has allowed scholars to create editable GS "profile pages" that it populates automatically with links to materials the author has written that are archived online. The profile page indicates how many times each item has been cited.

\section{Advantages of Google Scholar}

The advantages of GS stem primarily from its ease of use. A person's GS profile page provides a quick and convenient overview of their publications, rank-ordered by the number of citations of each publication. One can click on the hyperlinks of each publication 
to view abstracts and gain access to publicly available articles. Even articles that are stuck behind paywalls become more accessible, as the program regularly harvests open-source versions of the articles from other websites. GS's benefits include incentives for quality and visibility, academic coordination and open access, and consistency in research evaluation.

Incentives for quality and visibility. Academics are under never-ending pressure to "publish or perish." In the US, the tenure system puts a constant strain on faculty, particularly junior faculty. In the UK, this pressure has been institutionalized through the Research Excellence Framework (REF) system, which makes public funding to universities contingent on publications and "impact." ${ }^{4}$ The European Research Council asks all grant applicants to provide information about their "track record," including number of publications and citations. In this context, easy access to GS may provide incentives for scholars to emphasize quality over quantity. They may want to produce better publications that get cited more instead of more publications with fewer citations. Focusing on citation counts may also inspire authors to publicize their work more, such as through social media.

Academic coordination and open access to research. GS may facilitate the dissemination of ideas and intellectual networking. A GS search on a keyword can expose a reader to a new scholar, and the reader can easily see the scholar's other work through their GS profile. The citation count shows which of the author's articles and books are most popular. In addition, GS's automatic email notifications can encourage intellectual networking. Interested readers can sign up to receive automatic emails when scholars post new work, and scholars can get notified when somebody cites them, often at the workingpaper stage.

Our own personal experiences suggest that GS nudges scholars toward open-access practices (see also Hendrix 2016). When people see the convenient links to open-source versions of others' work, they may make their own work more publicly available, via their personal websites or on academic networking sites such as SSRN, Researchgate, and Academia.edu.

Consistency in research evaluation. The GS profile, with its full list of academic production, citation counts, and h-index, provides straightforward measures of scholarly quality and impact. These measures are highly reliable (anyone looking them up gets the same value) and consistent (the same coding scheme applies to all scholars). Given the 
prevalence of biases against women and people of color in the academy (see, e.g., Ginther et. al. 2011; Milkman, Akinola and Chugh 2012; Moss-Racusin et al. 2012), these measures offer grounds to challenge unfounded perceptions and prejudices.

And finally, the easy availability of citation counts can help scholars get credit for books and articles that are not published in the most famous outlets but are of intellectual importance. Citation counts can inform evaluators how the work has affected the field, independent of the publisher's prestige.

\section{Disadvantages of Google Scholar}

What explains the variation in citation counts across scholars and their scholarly work? Like all data, GS citation counts are produced through social and political processes. Most people would agree that good citation practices involve acknowledging prior work that helped generate ideas, and explaining how one's claims fit into a literature. However, recent studies show that these common-sense citation practices put pioneering scholars with bold ideas, early career scholars, scholars in smaller research communities, women, and solo authors at a disadvantage. Further, many people cite works for strategic rather than principled reasons. As a result, citation counts do not offer an accurate assessment of scholarly impact, and may exacerbate existing social hierarchies and inequalities. ${ }^{5}$

Originality and innovation. GS counts are biased toward incremental work and away from boldness and innovation. Highly original work that does not fit neatly into an existing literature might establish a new research agenda and expand interest in the topic, but its impact will not be visible in citation counts for many years. John Nash's foundational paper

defining Nash equilibrium received only 16 citations in the first five years after publication, according to GS.

To take another example, Stathis Kalyvas's article "Wanton and Senseless? The Logic of Massacres in Algeria" (Kalyvas 1999) was cited only 20 times (excluding author citations and citations from drafts of the same article) in the four years after its publication in 1999, despite winning the Luebbert Award in 2000. But its early citations came from a small group of colleagues who helped establish a new agenda in the field of civil war and ethnic conflict, including Elisabeth Wood, John Mueller, David Laitin, and James Fearon. Kalyvas's 
(2006) book on civil wars currently has over 3,000 citations, an impact impossible to predict from the 20 citations of the original 1999 article four years after its publication.

In general, the number of citations that an article or book receives in the five years or so after publication says little about its long-term impact. Wang, Song, and Barabasi (2013) looked at a sample of physics papers and found that having 50 citations in the first five years after publication was not associated with more citations after 20 years. In fact, papers with the most citations in 30 years tended to have relatively few citations early on. Stephan, Veugelers, and Wang (2017) examined 660,000 research articles in the Web of Science database, and found that highly original papers were less likely to be highly cited within three years of publication, but more likely to be highly cited three or more years after publication.

Early career scholars. Since hiring and promotion decisions occur fairly early in a scholar's career, citation counts may be more consequential precisely when they are least informative. Papers and books that are cited many years after publication are arguably more important than papers and books cited only shortly after publication. The time lag problem thus poses particular challenges to evaluating younger scholars.

Using GS to evaluate early-career scholars creates perverse incentives. From a numerical standpoint, it is better to publish incremental work on topics in which there is a large, active subgroup of scholars who cite one another than it is to open up a new field of research. Short-term, citation-centered evaluations discourage boldness and innovation, especially among early-career political scientists. Many important scholarly works initially defy easy contextualization and fit poorly into existing literatures, as the example of John Nash's paper shows. Tenure and promotion decisions that are based only or largely on citations garnered within five years of publication reward competence over lasting significance.

Research community size. Scholars in larger research communities have an advantage over scholars in smaller fields of study: they have a larger pool of people who can cite them. ${ }^{6}$ A paper cited in 16 out of 100 articles published in a given year on the US Congress probably has less "impact" than a paper cited in 8 of the 10 articles published that year on Pakistan, but it has double the count. Scholars producing incremental 
improvements in well-tilled fields thus tend to have larger citation counts than scholars producing novel insights in small but important or growing fields.

Gender. Maliniak, Powers, and Walter (2013) analyzed over two decades of publications in international relations (IR) and found that, controlling for a variety of factors such as publication venue, methodology, and tenure status, an article written by a woman receives 80 percent as many citations as a similar article written by a man. Women are less likely to be cited by the most influential articles, and less likely to self-cite, possibly because women experience penalties for self-promotion (Moss-Racusin and Rudman 2010).

Dion, Sumner, and Mitchell's (2018) study shows that women are more likely than men to cite works by women in multiple social science journals. In general, men and mixed author teams tend to undercite women's work, though the size of the gender citation gap varies according to the number of women in the field. As numbers of women scholars increase, work by women tends to get cited more by both men and women authors. They conclude that "citation practices are influenced by gender diversity" (Dion, Sumner, and Mitchell 2018).

Biases in favor of men can arise even if scholars genuinely cite those who influence them most. Colgan (2017) found that male IR instructors are less likely than female instructors to assign work by women scholars, while women are also less likely than men to assign their own work. Although there have been few systematic studies in political science on whether other underrepresented scholars experience similar biases, it is highly plausible that such biases exist.

Co-authorship. People who tend to co-author can generate citations more easily than people who tend to solo author. Citation counts are not divided by the number of coauthors: if a paper with five authors is cited once, each of the five authors receives one citation, not 0.2 citations. Higher citation counts for co-authoring scholars can exacerbate other biases. For example, Teele and Thelen (2017) demonstrate that all-male teams authored most of the collaborative work in ten of the most prominent political science journals. 
Strategic citation. Scholars face an array of professional imperatives: they want their work to appeal to reviewers, get published, and garner citations. They may thus engage in several forms of strategic citation (see Aizenman and Kletzer 2011).

Some books and articles are cited almost entirely for their flaws, not their importance. Authors often cite poorly-executed studies, easy targets, and straw-man pieces to explain what they are arguing against (Nexon and Jackson 2015). Journalists and policy analysts, in particular, may cite scholarship that generates splashy headlines and overlook less provocative work of higher quality (Colgan 2016).

Citation choices may also be guided by expectations of likely peer reviewers. Strategic citations include fellow members of academic networks likely to be favorably predisposed, producing a bias against citing scholars who are critical or outside those networks.

What is more, strategic citations may be driven by calculations about which works editors and reviewers will expect to see in the bibliography. Journal articles are increasingly subject to shorter word limits. Omitting citations helps, but authors do not want to be criticized for missing key works. This fear encourages "drive-by citations"citing papers merely because similar papers cite those papers, regardless of their actual relevance. Anecdotally, scholars who are cited in this way are often those whose work is repeatedly cited erroneously, for arguments they did not actually make.

Strategic citation leads people to cite authors of works already deemed important, not because of their relevance, but because they are perceived as gatekeepers, hold key editorial positions, or reside in powerful departments. Junior scholars have expressed concerns to us that their submissions to journals will face rejection if they anger prominent scholars by criticizing or not mentioning their work. Like the biases discussed above, strategic citation reproduces existing inequalities and disfavors underrepresented minorities, scholars from lower-ranked institutions, and people doing innovative work that does not neatly fit into existing literatures.

The disadvantages of GS do not foreclose its potential to serve as one indicator of scholarly impact, but require us to understand the factors that affect decisions about whom to cite. If departments, deans, and granting institutions look at GS counts, and external letter writers use them as a guide, citation numbers are effectively being counted twice or 
more, thus reducing the independence of external scholars' judgment. This doublecounting is particularly problematic when the data-generating process that leads to higher and lower citation counts has not yet been fully understood. Moreover, since a GS profile is a public signal, it can have disproportionate effect on people's opinions because a person seeing it knows that other people see it too (Chwe 2016).

\section{Conclusions}

GS has advantages: it promotes consistency in research evaluation, encourages transparency, publicity, and openness, makes it easier to gain access to scholarly work, facilitates networking among scholars, and may provide incentives for quality over quantity. On the other hand, GS citation counts favor incremental work, scholars in larger research communities, male-and likely white-scholars, scholars who co-author, and work that is cited strategically. While breaking down some doors, the uncritical use of GS entrenches long-existing inequalities in the political science discipline.

We recommend against the use of GS by external reviewers evaluating candidates for tenure and promotion. ${ }^{7}$ Their job is not to repeat information that anyone with access to the internet can obtain. Rather, it is to do work that most department members, deans, and provosts-actors who will continue to use GS as a shortcut-cannot. We rely on the judgment of external reviewers because they are experts in a candidate's field. They have a unique role and obligation to offer a reasoned, autonomous, and qualitative account of a scholar's contributions.

We are concerned that many academic departments and external reviewers, seduced by the ease of GS, are granting it unmerited importance in hiring, tenure, and promotion decisions. Since these decisions are vital for people's careers and lives, they should be based on data that are as accurate and balanced as possible. We are not against using GS, but caution that it should be only one piece of information we use to evaluate scholars, and only in conjunction with other means of assessment. As GS grows in importance, so does the need for autonomous scholarly judgment. 


\section{References}

Aizenman, Joshua, and Kenneth Kletzer. 2011. "The Life Cycle of Scholars and Papers in Economics - the 'Citation Death Tax'." Applied Economics 43(27):4135-4148.

Chwe, Michael Suk-Young. 2016. "Stereotypes Are More Powerful When People Like to Agree with Each Other." Working paper, UCLA. Last modified September 30. PDF file.

Colgan, Jeff. 2016. "Where Is International Relations Going? Evidence from Graduate Training." International Studies Quarterly 60 (3):486-498.

Colgan, Jeff. 2017. "Gender Bias in International Relations Graduate Education? New Evidence from Syllabi.” PS: Political Science \& Politics 50 (2):456-460.

Dion, Michelle, Jane Lawrence Sumner, and Sara McLaughlin Mitchell. Forthcoming. "Gendered Citation Patterns Across Political Science and Social Science Methodology Fields." Political Analysis.

Ginther, Donna K., Walter T. Schaffer, Joshua Schnell, Beth Masimore, Faye Liu, Laurel L. Haak, and Raynard Kington. 2011. "Race, Ethnicity, and NIH Research Awards." Science 333 (6045):1015-1019

Hendrix, Cullen. 2015. “Google Scholar Metrics and Scholarly Productivity in International Relations." Duck of Minerva, Aug 6. http://duckofminerva.com/2015/08/google-scholarmetrics-and-scholarly-productivity-in-international-relations.html

Hendrix, Cullen. 2016. "To Be or Not to Be, "Tis in Question." In "Scholarly Influence and the Shaping of International Relations Debates." International Studies Quarterly Symposium, March 31.

Henrekson, Magnus, and Daniel Waldenstrom. 2011. "How Should Research Performance Be Measured? A Study of Swedish Economists." The Manchester School 79(6):1139-1156.

Jacsó, Peter. 2005. "Google Scholar: The Pros and the Cons." Online Information Review 29 (2):208-14.

Kalyvas, Stathis N. 1999. "Wanton and Senseless? The Logic of Massacres in Algeria." Rationality and Society 11(3): 243-85.

Kalyvas, Stathis N. 2006. The Logic of Violence in Civil War. New York: Cambridge University Press.

Maliniak, Daniel, Ryan Powers, and Barbara F. Walter. 2013. "The Gender Citation Gap in International Relations." International Organization, 67(4):889-922.

Milkman, Katherine L., Modupe Akinola, and Dolly Chugh. 2012. "Temporal Distance and Discrimination: An Audit Study in Academia." Psychological Science 23 (7):10-717. 
Moss-Racusin, Corinne A., and Laurie A. Rudman. 2010. "Disruptions in Women's SelfPromotion: The Backlash Avoidance Mode." Psychology of Women Quarterly, 34(2):186202.

Moss-Racusin, Corinne A., John F. Dovidio, Victoria L. Brescoll, Mark J. Graham, and Jo Handelsman. 2012. "Science Faculty's Subtle Gender Biases Favor Male Students." Proceedings of the National Academy of Sciences 109(41):16474-16479

Nexon, Daniel, ed. 2016. "Scholarly Influence and the Shaping of International Relations Debates." International Studies Quarterly Symposium, March 3. https://www.isanet.org/Publications/ISQ/Posts/ID/5107/Scholarly-Influence-and-theShaping-of-International-Relations-Debates

Nexon, Daniel, and Patrick Thaddeus Jackson. 2015. "Academia Isn't Baseball." Duck of Minerva, August 10. http://duckofminerva.com/2015/08/academia-isnt-baseball.html

Ray, Debraj, and Arthur Robson. 2016. "Certified Random: A New Order for Co-Authorship." American Economic Review 108(2):489-520.

Reiter, Dan. 2016. “Citation Count Data and Faculty Promotion.” Duck of Minerva, Feb 18. http://duckofminerva.com/2016/02/citation-count-data-and-faculty-promotion.html

Samuels, David. 2011 "The Modal Number of Citations to Political Science Articles Is Greater Than Zero: Accounting for Citations in Articles and Books." PS: Political Science \& Politics 44(4):783-792.

Samuels, David. 2013. "Book Citations Count." PS: Political Science \& Politics 46(4):785-790.

Stephan, Paula, Reinhilde Veugelers and Jian Wang. 2017. "Reviewers are Blinkered by Bibliometrics." Nature 544(7651):411-412.

Teele, Dawn Langan, and Kathleen Thelen. 2017. "Gender in the Journals: Publication Patterns in Political Science." PS: Political Science \& Politics 50(2):433-447.

\footnotetext{
${ }^{1}$ See Reiter's (2016) report on the use of citation data for promotion decisions in departments with political scientists.

2 The authors of this article are not in complete agreement on all points.

3 See "About Google Scholar," at https://scholar.google.com/intl/en/scholar/about.html. Accessed April 5, 2018.

4 See http://www.hefce.ac.uk/rsrch/funding/

5 There are additional concerns about the accuracy of GS counts. GS appears to vacuum up virtually everything on the web without any quality control. Reiter (2016) has suggested that this inclusivity leads to overcounting. For instance, Samuels (2011) found that one of his journal articles had 80 citations according to GS, but six of them were duplicate entries and 52 were unpublished works. No outsider can improve the tool, since Google does not disclose its algorithms. Overcounting can result from the existence of multiple online versions of an article, subtle variations in bibliographic format, and the accidental inclusion of articles written by others. Scholars can also edit their own GS citation count data, which may lead to some manipulation of the
} 
citation count (Reiter 2016), for instance through adding or failing to delete false positives. GS may also undercount. Samuels also found that 5 of the 80 citations to his article in GS were books. However, according to the Google Books database-a separate database not linked to Google Scholar-the article was cited in 24 books. Undercounting of citations in books may decline as more material is entered into the GS database over time. (Samuels found no difference in book citations to that same article in 2017, while a difference did appear in 2010.) But since the methodology is not public, self-correction over time cannot be assumed. To the extent that GS still undercounts citations that books receive or of articles in books, GS may understate the impact of scholars who publish more in books than in articles (Samuels 2013).

${ }^{6}$ Reiter (2016) also points to variation in the size of the citation pool across political science subfields, rendering problematic comparisons of scholars in different subfields.

7 We know that many external reviewers will continue to use GS in the course of doing research about candidates for tenure and promotion. We are not recommending that they stop this practice, but rather that they do not include GS and other citation counts in their written evaluations. However, the authors of this article are not in complete agreement on this point. 